\title{
Heterochromatin: stable and unstable invasions at home and abroad
}

\author{
Jill A. Fahrner and Stephen B. Baylin ${ }^{1}$ \\ The Sidney Kimmel Comprehensive Cancer Center at Johns Hopkins, Baltimore, Maryland 21231-1000, USA; The Graduate \\ Program in Cellular and Molecular Medicine, The Johns Hopkins University School of Medicine, \\ Baltimore, Maryland 21231, USA
}

One of the most vibrant areas of biology at present concerns elucidation of the "epigenetic" molecular mechanisms underlying how genomes are packaged to facilitate heritable gene expression patterns. An explosion of recent findings reveals how various components of chromatin regulate this process. Especially exciting is the dynamic role played by histone posttranslational modifications, which some have termed the "histone code" (Strahl and Allis 2000; Jenuwein and Allis 2001; Kouzarides 2002). Equally important are the proteins that read this code and interpret the signals to modulate transcriptional potential (Eissenberg and Elgin 2000; Lachner et al. 2001). Much of what we have learned about these molecular parameters has come from the study of large regions of DNA packaged into, and heritably transmitted as, permanently transcriptionally silenced regions termed constitutive heterochromatin (Wakimoto 1998; Grewal and Elgin 2002). In classic studies with Drosophila, molecular determinants have been elucidated to explain variegated patterns of heritable gene expression, or position effect variegation (PEV), which emerge when a gene that normally resides in active euchromatin is translocated into such heterochromatin (Wallrath and Elgin 1995; Wakimoto 1998; Grewal and Elgin 2002). In this issue of Genes \& Development, a clever experimental system initially designed to explore the role of heterochromatin in the silencing of specific genes unexpectedly reveals that the opposite situation, invasion of heterochromatin into a euchromatic region, also triggers a variegated pattern of heritable gene silencing (Аyyanathan et al. 2003). These findings have important ramifications for gene expression in settings of both normal and pathological cellular function.

\section{Sharing the players to form different types of heterochromatin}

The paper by Ayyanathan et al. (2003) is highly relevant to rapidly changing concepts about whether heterochro-

${ }^{1}$ Corresponding author.

E-MAIL sbaylin@jhmi.edu; FAX (410) 614-9884.

Article and publication are at http://www.genesdev.org/cgi/doi/10.1101/ gad.1123303. matin always occupies exclusive domains of the genome distinct from euchromatin. If so, this would logically suggest that the players and mechanisms involved in forming heterochromatin would not be found in euchromatin. Indeed, dominance for the heterochromatin zone in PEV in flies is dependent on the action of key players in the histone code concept, hypoacetylation of key histone amino acid residues and methylation of Lys 9 of histone H3 (methyl-H3-K9; Ahmad and Henikoff 2002a; Richards and Elgin 2002). The proteins, which when mutated suppress PEV, include Su(var)3-9, a histone methyltransferase (HMT) that establishes and maintains methyl-H3-K9, and Su(var)2-5, the Drosophila homolog of the mammalian heterochromatin protein 1 (HP1). HP1 provides a critical readout of methyl-H3-K9 (Grewal and Elgin 2002; Lachner and Jenuwein 2002; Richards and Elgin 2002) and is essential for the spread of heterochromatin into, and maintenance within, the gene unstably silenced in PEV (Lachner and Jenuwein 2002; Richards and Elgin 2002).

In keeping with the idea of euchromatin and heterochromatin as separate domains, many of the determinants of heterochromatin critical for PEV in flies, including deacetylated histones, methyl-H3-K9, the homologs of Su(var)3-9, and HP1, have now been localized to large areas of heterochromatin in pericentromeric and/or telomeric regions in multiple organisms (Jacobs et al. 2001; Nakayama et al. 2001; Lachner and Jenuwein 2002). Indeed, genetic disruption in mice of the HMTs SUV39h1 and SUV39h2 and subsequent methyl-H3-K9 displacement result in disruption of pericentromeric heterochromatin (Peters et al. 2001). Also, with respect to separate zones of the genome, albeit smaller in size, in chickens and yeast, histone posttranslational modifications linked to heterochromatin sharply demarcate broad regions of silenced genes from adjacent regions of expressed genes (Litt et al. 2001; Noma et al. 2001; Hall et al. 2002).

There is a new twist in the story, however, in that silencing of individual genes residing in euchromatin can involve establishment of small microcosms of heterochromatin. For example, methyl-H3-K9 and/or methyl-H3-K27 have now been mapped to small regions encompassing the promoters of individually silenced 
genes on the mammalian inactive $\mathrm{X}$ chromosome (Boggs et al. 2002; Plath et al. 2003), silenced imprinted alleles (Xin et al. 2003), and genes aberrantly silenced in cancer cells (Fahrner et al. 2002; Ghoshal et al. 2002; Nguyen et al. 2002; Kondo et al. 2003). HP1 has also been associated with gene silencing in euchromatic regions (Hwang et al. 2001; Nielsen et al. 2001; Li et al. 2002). The findings of Ayyanathan et al. (2003) extend the link between formation of heterochromatin and silencing of genes in euchromatic regions. The work goes back to findings in the Rauscher lab that HP1 can reside in a complex with the transcriptional corepressor KAP1 and other key heterochromatin players, including the methyl-H3-K9 HMT, SETDB1, and a histone deacetylase (HDAC)-containing complex (Schultz et al. 2001, 2002). The KAP1 complex is targeted to promoters by partnering with the highly conserved KRAB domain, which is found in a large family of zinc-finger transcriptional repressors (Schultz et al. 2001, 2002).

In their present paper, the authors find that both inducible targeting of a KRAB fusion protein to an integrated reporter gene and sustained targeting of an endogenous KRAB-domain-containing protein to its constitutively repressed target gene result in very localized heterochromatin formation at promoters. Whereas the $\mathrm{KRAB}$ domain is localized predominantly to specific binding sites upstream of the promoters, KAP1, HP1, SETDB1, and methyl-H3-K9 occur not only at these sites but also just downstream, surrounding the proximal promoter. Importantly, the promoter of an expressed gene near the endogenous gene and a gene $<3 \mathrm{~kb}$ downstream from the reporter gene in the exogenous target construct contain none of the heterochromatin marks. Furthermore, for the exogenous reporter gene, the promoter region exclusively adopts a closed chromatin conformation. Finally, the stably integrated reporter gene, even with only relatively acute repressor complex binding and silencing, actually changes localization in the nucleus from euchromatin to a large heterochromatin domain.

How can we now view formation of very large versus discrete regions of heterochromatin? First, the major players, clearly, can multitask in forming heterochromatin in multiple genomic regions. Second, the establishment of both small and large domains of heterochromatin appears to depend integrally on particular DNA sequence elements. For the events described by Ayyanathan et al. (2003), occupancy of discrete transcription-factor-binding sites starts the process. For very large domains, such as in pericentromeric regions, stretches of DNA repeats appear to be key, and RNA species are the initiating factors. For example, in the case of centromeres (Volpe et al. 2002) and the silent mating locus (Hall et al. 2002) in Schizosaccharomyces pombe, DNA sequence repeats may be transcribed, creating double-stranded RNAs (dsRNAs), which are then processed by the RNA interference (RNAi) machinery (Hall et al. 2002; Volpe et al. 2002). The resultant small interfering RNAs (siRNAs) may guide methyl-H3-K9 to the region (Volpe et al. 2002), which then targets Swi6, the $S$. pombe homolog of mammalian HP1 (Nakayama et al.
2001). Mammalian pericentromeric heterochromatin formation and maintenance may also depend on RNA species, as methyl-H3-K9 staining and HP1 $\alpha$ localization can be disrupted upon RNase A treatment and restored by the addition of RNA (Maison et al. 2002). RNA species may also play a role in the formation of smaller heterochromatin zones and initiate silencing for inactive X-chromosome genes (Csankovszki et al. 2001; Willard and Carrel 2001) and silenced imprinted alleles (Tilghman 1999). Intriguingly, in a genetic form of anemia, an antisense RNA expressed from a sequence juxtaposed to a normal $\alpha$-globin gene via a deletion initiates, during development, abnormal silencing and promoter $\mathrm{CpG}$ island methylation for the otherwise normal gene (Tufarelli et al. 2003).

\section{Heterochromatin invasions into euchromatin- establishing both stable and unstable outcomes abroad}

Although the Ayyanathan studies (Ayyanathan et al. 2003) provide important insight into the construction of heterochromatin for local gene-silencing events, what do they have to do with heritable transmission of these states? This aspect involves the two most surprising findings in the studies. The heterochromatin initiates not only heritable silencing of the individual promoter of the experimental construct, but also the silencing occurs in a variegated pattern with some features of PEV. Depending on the duration of time of exposure to induced KRAB-KAP1 binding and transcriptional repression, the stably integrated reporter gene maintains a durable silencing for at least 40 cell doublings. However, some individual clones fully escape long-term silencing, others show intermediate silencing, and yet others have virtually complete silencing. The silencing is tightly linked to retention of the microcosm of proximal promoter heterochromatin at the reporter gene.

One fascinating aspect of the variegation is that the $\mathrm{KRAB}$ domain triggers, at least in terms of amount of binding, a relatively "hit and run" scenario. Thus, binding of the protein is very low in the silenced clones but leaves behind enrichment of KAP1, SETDB1, methyl$\mathrm{H} 3-\mathrm{K} 9$, and significantly, HP1 $\alpha / \gamma$. Furthermore, this variegated heritable state may be essentially HP1-familydependent. Induced binding of several other types of transcriptional repressors, whose associated complexes contain no HP1 proteins, targets and transiently silences the reporter gene, but the silencing is not heritable. Finally, the KRAB/KAP1-mediated heritable transcriptional silencing induces in the most silenced clones a mechanism used in mammalian heterochromatin. Extensive DNA methylation is found in a CpG-rich region localized in the $5^{\prime}$ portion of the promoter driving the reporter gene.

Although Ayyanathan et al. (2003) suggest that heterochromatin invading euchromatin can set up gene silencing that is unstable, is this always the case? There is, alternatively, precedence that stable silencing, which benefits the organism, can arise in a somewhat similar scenario. A small domain on rat chromosome 3q22-32 
contains five genes important for neural development that are regulated by the zinc-finger repressor element REST/NRSF, which is required for repression of neuronal-specific genes in nonneuronal tissues (Lunyak et al. 2002). The binding site for REST/NRSF, RE-1/NRSE, is present in the promoters of only three of the five genes in the locus. Yet binding of REST/NRSF and its corepressor CoREST at these three sites results in stable recruitment of DNA methylation, methyl-H3-K9, and a complex containing the methyl-CpG-binding protein (MBP) MeCP2, and presumably HP1 $\alpha$ and SUV39H1, to the promoters of all five genes. This heterochromatin formation results in their permanent silencing, which facilitates nonneural lineage restriction (Lunyak et al. 2002).

Although the above scenario shares features of the silencing observed by Ayyanathan et al. (2003), key differences lie in the stability of the transcriptional repression and the distribution of the heterochromatin. For the neural genes, transcriptional repressor binding remains prominent at its discrete binding sites, but the resulting zone of heterochromatin spreads and silences two additional genes. It is as if, in the experimental system of Ayyanathan et al. (2003), the generals (the KRAB domain) bring in the army (heterochromatin machinery) to a specific site, transiently secure the area, and then leave the army with reduced leadership, resulting in an unstable environment (variegated silencing). In contrast, in the more stable invasion of euchromatin by heterochromatin involving the neural genes, the generals and the army remain and truly secure the zone.

The above discussions of stability versus instability imply that the type of variegated gene silencing produced in the studies of Ayyanathan et al. (2003) may best reflect, at least in the short run, situations of potential harm to the organism. This may be the case for variegated gene silencing established either when euchromatin invades heterochromatin or vice versa. For the former, it must be remembered that the classic situation for this phenomenon, PEV in flies, was originally observed following $\mathrm{X}$-irradiation-induced gene translocations (Ahmad and Henikoff 2002a). In this setting, the ensuing dynamics, rather than reflecting a hit-and-run situation, result from an ongoing battle in cells of the developing eye between euchromatic and heterochromatic boundaries separating the invaded heterochromatin from the euchromatic gene promoter (Wallrath and Elgin 1995; Sun and Elgin 1999; Ahmad and Henikoff 2002a).

If hit-and-run invasion of heterochromatin into euchromatin establishes pathologic states of gene expression, then cancer may be the hallmark example in which this occurs. Tumor suppressor genes can be inappropriately transcriptionally silenced in association with dense DNA hypermethylation of promoter CpG islands in virtually all human tumor types, thus providing an alternative to coding region mutations for loss of gene function (Jones and Baylin 2002). The dynamics for evolution of these tumor changes have similarities to those reported by Ayyanathan et al. (2003). This is seen for one tumor suppressor gene, CDKN2A/p16 $6^{I N K 4 a}(p 16)$, for which loss of function is particularly easily selected because it allows normally quiescent cells to keep growing (Sherr 1996). The DNA hypermethylation and transcriptional silencing of this and other cancer genes can be experimentally disrupted by genetically deleting two of the three mammalian DNA methyltransferases (DNMT), DNMT1 and 3b, from human colorectal cancer cells (Rhee et al. 2002). However, with time, the p16 gene resilences, and growth of the cells accelerates. In this setting, methyl-H3-K9 is the first heterochromatic mark to appear at the $p 16$ gene promoter, and its presence correlates with initial gene resilencing (Bachman et al. 2003). DNA methylation and histone deacetylation ensue later and appear to strengthen the silencing because the cells further accelerate toward the wild-type cell growth rate (Bachman et al. 2003).

The steady-state epigenetic silencing of other cancer genes also bears striking similarities to the findings of Ayyanathan et al. (2003). First, the promoters of these genes, in addition to DNA hypermethylation, have a resident zone of methyl-H3-K9 and histone deacetylation (Fahrner et al. 2002), whereas nearby genes may have no such silencing marks (Nguyen et al. 2002). Also, in contrast to the initial mark, which seems to be enrichment of methyl-H3-K9, or an earlier as-yet-unidentified event leading to this histone modification, DNA methylation does not seem to initiate silencing (Bachman et al. 2003). However, this heterochromatin feature appears integral to the heritable silenced state. Upon treatment with the DNMT inhibitor 5-Aza-2'-deoxycytidine (DAC), multiple hypermethylated, silenced tumor suppressor genes are transcriptionally reactivated, demethylated at multiple CpG sites, depleted of methyl$\mathrm{H} 3-\mathrm{K} 9$, and reacetylated at $\mathrm{H} 3-\mathrm{K} 9$ and $\mathrm{H} 3-\mathrm{K} 14$ (Fahrner et al. 2002; Ghoshal et al. 2002; Nguyen et al. 2002; Kondo et al. 2003). Such loss of the heterochromatinestablishing machinery, including the methyl-H3-K9 mark and the SETDB1 HMT, follows demethylation in the studies of Ayyanathan and coworkers (Ayyanathan et al. 2003). Another similarity between epigenetically silenced cancer genes and the silencing events shown by Ayyanathan et al. (2003) is that the HDAC inhibitor Trichostatin A (TSA) will not reactivate the genes unless DNA demethylation is first initiated by treating cells with a low dose of DAC. This treatment paradigm appears to be a universal property of epigenetically silenced cancer genes containing dense promoter DNA methylation (Cameron et al. 1999; Suzuki et al. 2002).

Why does DNA methylation become part of the above gene silencing, and how is it targeted to promoters? The presence of methyl-H3-K9 appears to be the key. In both Neurospora crassa and Arabidopsis thaliana, elegant studies show that this mark serves as a beacon for DNA methylation and that mutations in HMTs, which establish this histone modification, abolish DNA methylation (Tamaru and Selker 2001; Jackson et al. 2002). Once established, DNA methylation may facilitate the maintenance of silencing in multiple ways. As possibly the most stably propagated mark, it may target other heterochromatin players back to the DNA after replica- 
Fahrner and Baylin

A

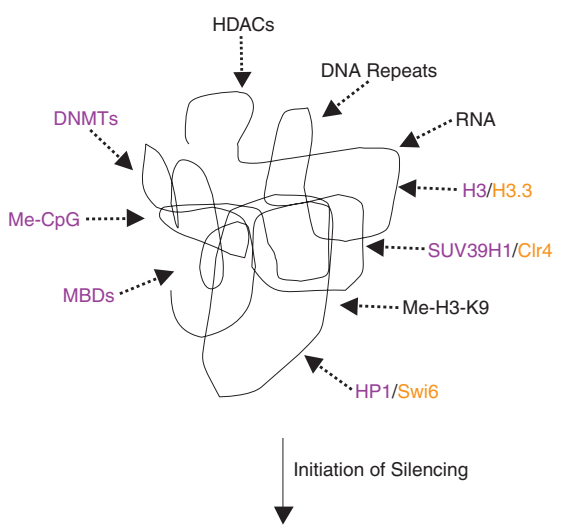

Localization to highly condensed region Silent, Late Replicating
B

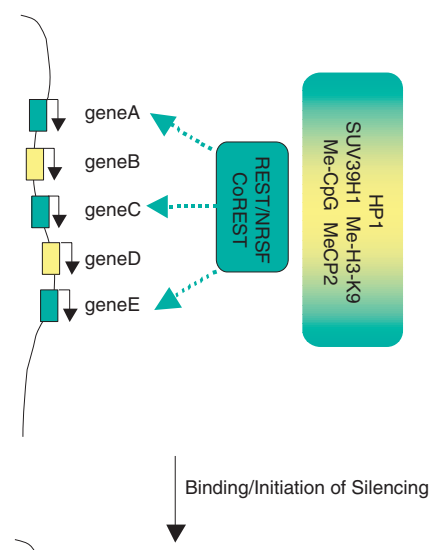

Multiple Rounds of
Replication


Localization to highly condensed region Silent, Late Replicating

C
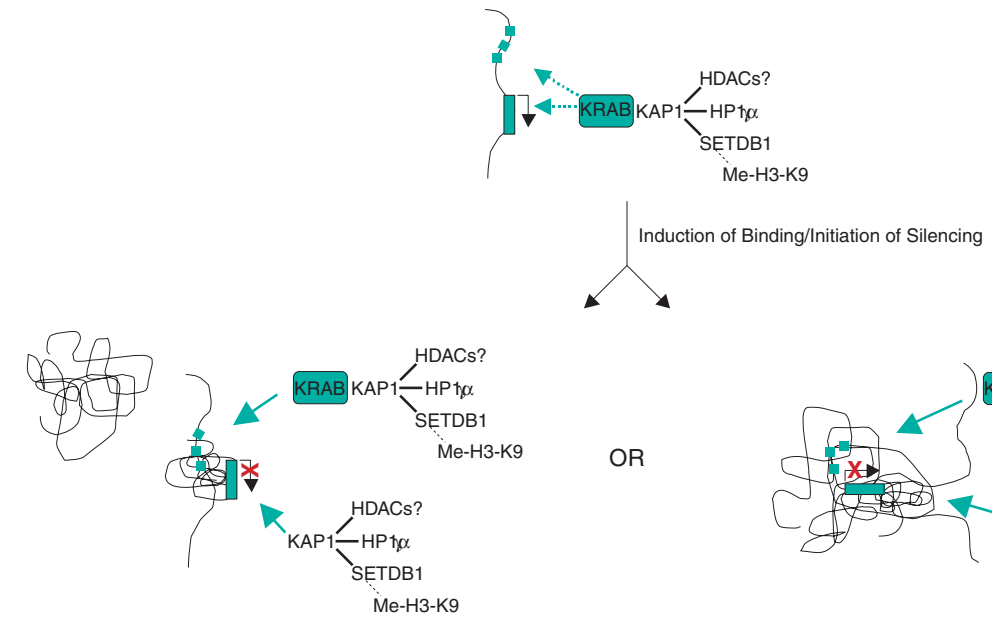

OR
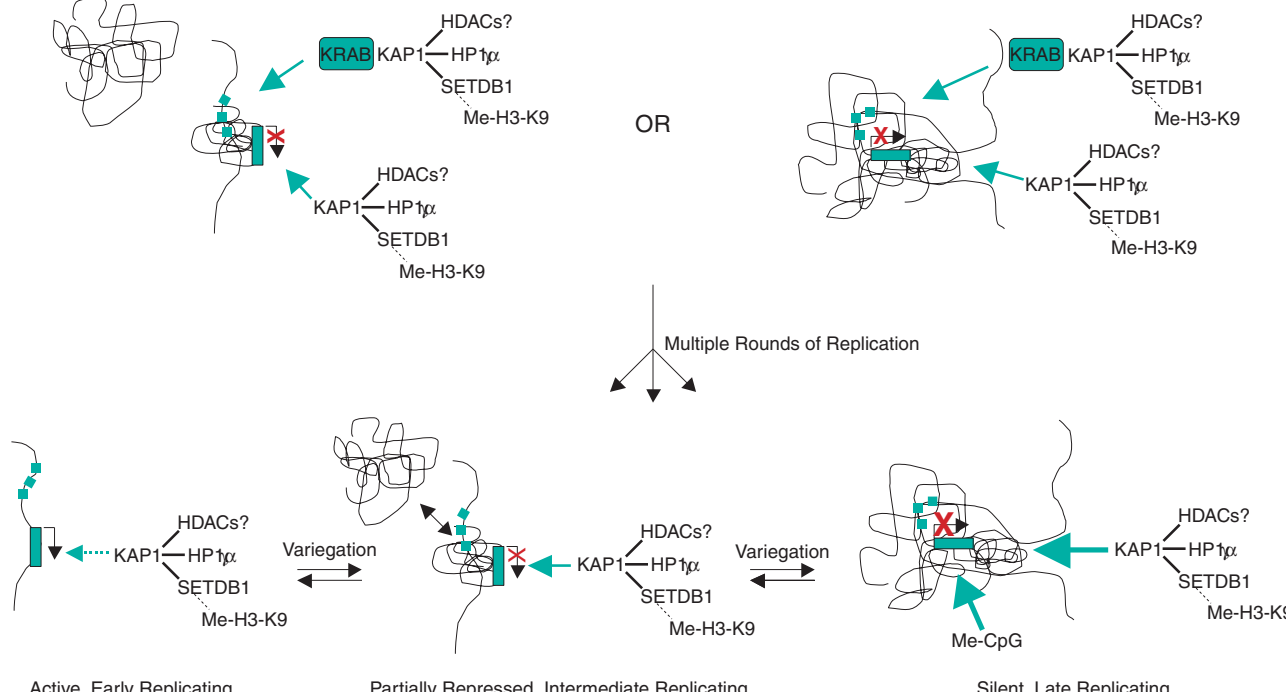

Active, Early Replicating

Partially Repressed, Intermediate Replicating

Silent, Late Replicating

Figure 1. (Figure 1 legend on facing page)

tion. For example, mammalian DNMTs and MBPs can potentially recruit HDACs to heterochromatin (Fuks et al. 2000; Robertson et al. 2000; Rountree et al. 2000;
Bachman et al. 2001; Bird 2002; Deplus et al. 2002). This can help maintain deacetylation of histone $\mathrm{H} 3$, and thus methylation of H3-K9. Furthermore, DNMT1 and 3a 
have been shown to associate with an HP1 protein in vitro (Fuks et al. 2003), and complexes between HMTs and DNMTs have now been reported (Burgers et al. 2002; Datta et al. 2003; Fuks et al. 2003). Some H3-K9-specific HMTs, like SETDB1, contain MBP domains, which may promote binding to methylated DNA (Kouzarides 2002). CMT3, an Arabidopsis DNMT, can bind HP1, which also interacts with methyl-H3-K9, further linking histone and DNA methylation (Jackson et al. 2002). All of the above factors could constitute a circle of events to perpetuate heterochromatin. In the Ayyanathan et al. (2003) studies, interaction of DNA methylation, HP1, and methyl-H3-K9 could facilitate silencing of the initial localized heterochromatin zone by recruiting it to a larger region of late-replicating heterochromatin.

In situations of variegated epigenetic silencing that facilitate a pathologic process such as cancer, it must be remembered that, unlike for expression of an exogenous reporter gene that does not affect cell growth and survival, the variance in the degree of gene expression may be tempered by the nature of the gene. For example, as mentioned, selection for effects of loss of gene function may be particularly powerful for a growth suppressor gene like $p 16$. In this case, the epigenetic mark of DNA methylation may actually act to suppress the degree of variegation by helping to reduce the gene expression to the lowest possible levels in all cells. In contrast, for the tumor suppressor gene E-cadherin, which favors cell invasion when lost, but which is required for cells to grow in metastatic sites, epigenetic variegation would be helpful for tumor progression. Indeed, both in culture and in primary tumors, marked variability of promoter DNA methylation and cell heterogeneity for expression of this protein are observed and can be manipulated by the environment (Graff et al. 2000).

Finally, DNA methylation and tight gene silencing may be linked to, and prevent, a key step in transcriptional gene activation involving nucleosome replace- ment. In flies and probably other organisms, activation of transcription is accompanied by DNA replication-independent substitution of the variant histone H3.3 for H3 (Ahmad and Henikoff 2002b). This would include removal of the methyl-H3-K9 mark, allowing for re-establishment and maintenance of $\mathrm{H} 3$ acetylation. This is a critical finding because direct enzymatic removal of histone methylation has not been documented and is not predicted to be a favorable reaction (Jenuwein 2001; Bannister et al. 2002). Thus, nucleosome replacement may explain why, in Arabidopsis, there is loss of methyl-H3K9 following DNA demethylation, but only at sites where transcription is derepressed (Johnson et al. 2002). This fits nicely with our own studies of a DNA hypermethylated tumor suppressor gene, wherein DAC treatment leads to DNA demethylation first, gene reactivation second, and only then is substantial loss of methylH3-K9 and accumulation of acetylated H3-K9 and H3K14 observed (Fahrner et al. 2002). As Ahmad and Henikoff (2002a) point out, once variant H3.3 is introduced at the promoter, levels can build independently of DNA replication, with successive rounds of transcription, and this would markedly blunt the establishment of epigenetic gene silencing. These events may well explain the failure of TSA alone to reactivate DNA hypermethylated genes (Cameron et al. 1999) because DNA demethylation may be required to allow buildup of H3.3, which would then respond to protection from histone deacetylation.

\section{Bringing together the many faces of heterochromatin}

How might we broadly summarize the establishment and maintenance of all the various states of heterochromatin discussed? Perhaps we can visualize at least three types of heterochromatin (Fig. 1). The first would be large domains of constitutive heterochromatin, which are stably maintained separately from euchromatin by the heterochromatin machinery discussed (Fig. 1A). The

Figure 1. Models for heterochromatin formation. (A) Constitutive heterochromatin is formed in large domains (large squiggles) as discussed in the text and is stably maintained during DNA replication and cell division. For key components of the heterochromatin machinery, mammalian pericentromeric components are indicated in purple, Schizosaccharomyces pombe centromeric components in orange, and those present in both in black. (B) Example of heterochromatin invading euchromatin as discussed in the text for a chromosomal interval containing five neural genes, which are stably silenced in nonneuronal tissues. The REST/NRSF-CoRest complex (indicated by a labeled green rectangle) binds specifically to binding sites in the promoters of genes A, C, and E, indicated in green, but has no binding sites in the promoters of genes B and D, indicated in yellow. However, the REST/NRSF-CoRest complex recruits the heterochromatin machinery discussed in the text (indicated by a shaded green and yellow rectangle) to a limited region encompassing, and silencing (red X), all five genes, thus forming a localized domain of facultative heterochromatin surrounded on both sides by euchromatin (thin black line). Once formed, the heterochromatin in $A$ and $B$ most likely localizes to highly condensed, heterochromatic regions of the nucleus and becomes late replicating. $(C)$ Invasion of heterochromatin into euchromatin to establish heritable but variegated gene silencing. The top panel represents initial targeting of a KRAB-domain-containing protein (green box) to specific upstream binding sites (three small green squares) and to the proximal promoter of an initially expressed euchromatic gene (green rectangle with arrow). The KRAB domain recruits the transcriptional repressor KAP1 and heterochromatin formation machinery to the binding sites to induce the silent state (middle panel), in which the KRAB domain remains bound exclusively to the specific binding sites, while these other heterochromatin players remain enriched at both the upstream binding sites and at the transcription start site. The bottom panel shows, as discussed in the text, that during subsequent cell renewal, this microcosm of heterochromatin is fully reversed (left), remains as a microcosm of heterochromatin for an intermediate level of reversible gene silencing (middle), or is recruited to large domains of late replicating heterochromatin, resulting in a permanently silenced state (right). In $A, B$, and $C$, broken arrows indicate targeting of the silencing complexes, whereas filled arrows indicate actual binding of the repressor complexes to the DNA, with increasing size of the arrows indicating increased binding. 
other two are related, but different situations, wherein heterochromatin invades otherwise euchromatic areas. One is the stable gene expression switch that we reviewed involving developmental cell lineage restriction (Fig. 1B; Lunyak et al. 2002). The other is the unstable heritable state depicted by the findings of Ayyanathan et al. (2003), which we have suggested plays a role in pathologic events (Fig. 1C).

For pathologic states, what would convert the normal transient silencing event to an abnormal heritable and unstable one? As shown by Ayyanathan et al. (2003), cell division and timing of replication for an involved gene may be critical. Normally expressed or readily inducible genes replicate early in the cell cycle, reside in more euchromatic domains, and escape permanent heterochromatin formation when transiently silenced. An example would be Rb/SUV39H1-mediated repression of cyclin E expression during the cell cycle with local recruitment of HP1 and methyl-H3-K9 to the promoter (Nielsen et al. 2001). In a state such as cancer, in which a fundamental property is failure to prevent cell renewal (Sherr 1996), or even in cancer predisposition states such as chronic injury and inflammation involving pressure for continued cell renewal, a window for establishment of epigenetic silencing may be established. Normal cycling of transactivating factors, which might otherwise counteract normal transient gene silencing events, may be disrupted. Thus, there would be failure to reverse transiently established local heterochromatin zones through replication-independent nucleosome replacement and loss of methyl-H3-K9 to allow reacetylation and block gene silencing until again needed. Also, during perpetual cell renewal, there might be increases in cellular levels of HP1 and other components of the heterochromatin machinery, including capacity for DNA methylation. If such factors are even modestly elevated, heterochromatin could be abnormally targeted to extend and/or maintain epigenetic gene silencing. This occurs at telomeric and mating loci regions in yeast when silencing factor levels are altered (Kimura et al. 2002; Suka et al. 2002) and for PEV in flies with changing HP1 levels (Hwang et al. 2001). There is precedence for increases in many such factors in cancer cells, including partners for HMTs (Varambally et al. 2002), HP1 (Li et al. 2002), and DNMTs (Issa et al. 1993; De Marzo et al. 1999; Robertson et al. 1999). In this regard, it must be remembered that the cells used by Ayyanathan et al. (2003), mouse NIH3T3 cells, have many premalignant properties, including being immortalized and being readily transformable. Would the hit-and-run events seen have occurred in fully normal cells?

The models in Figure 1, particularly for variegated silencing, are working hypotheses only, and there will be much excitement to come as all of the molecular players and actual inciting events for this fascinating aspect of epigenetics are identified. The experimental model of Ayyanathan et al. (2003) provides one excellent example of the tools that can be used to help piece all of this together. The thinking behind the use of the systems, and the dissection of events observed, must and should be as dynamic as the processes of chromatin formation and maintenance are proving to be.

\section{Acknowledgments}

We thank Kevin Pruitt, Ph.D., for reading the manuscript. We apologize to those whose work was not cited due to space limitations.

\section{References}

Ahmad, K. and Henikoff, S. 2002a. Epigenetic consequences of nucleosome dynamics. Cell 111: 281-284.

- 2002b. The histone variant H3.3 marks active chromatin by replication-independent nucleosome assembly. Mol. Cell 9: 1191-1200.

Ayyanathan, K., Lechner, M.S., Bell, P., Maul, G.G., Schultz, D.C., Yamada, Y., Tanaka, K., Torigoe, K., and Rauscher III, F.J. 2003. Regulated recruitment of HP1 to a euchromatic gene induces mitotically heritable, epigenetic gene silencing: A mammalian cell culture model of gene variegation. Genes \& Dev. (this issue).

Bachman, K.E., Rountree, M.R., and Baylin, S.B. 2001. Dnmt3a and Dnmt3b are transcriptional repressors that exhibit unique localization properties to heterochromatin. J. Biol. Chem. 276: 32282-32287.

Bachman, K.E., Park, B.H., Rhee, I., Rajagopalan, H., Herman, J.G., Baylin, S.B., Kinzler, K.W., and Vogelstein, B. 2003. Histone modifications and silencing prior to DNA methylation of a tumor suppressor gene. Cancer Cell 3: 89-95.

Bannister, A.J., Schneider, R., and Kouzarides, T. 2002. Histone methylation: Dynamic or static? Cell 109: 801-806.

Bird, A. 2002. DNA methylation patterns and epigenetic memory. Genes \& Dev. 16: 6-21.

Boggs, B.A., Cheung, P., Heard, E., Spector, D.L., Chinault, A.C., and Allis, C.D. 2002. Differentially methylated forms of histone $\mathrm{H} 3$ show unique association patterns with inactive human X chromosomes. Nat. Genet. 30: 73-76.

Burgers, W.A., Fuks, F., and Kouzarides, T. 2002. DNA methyltransferases get connected to chromatin. Trends Genet. 18: $275-277$.

Cameron, E.E., Bachman, K.E., Myohanen, S., Herman, J.G., and Baylin, S.B. 1999. Synergy of demethylation and histone deacetylase inhibition in the re-expression of genes silenced in cancer. Nat. Genet. 21: 103-107.

Csankovszki, G., Nagy, A., and Jaenisch, R. 2001. Synergism of Xist RNA, DNA methylation, and histone hypoacetylation in maintaining $\mathrm{X}$ chromosome inactivation. I. Cell Biol. 153: $773-784$.

Datta, J., Ghoshal, K., Sharma, S.M., Tajima, S., and Jacob, S.T. 2003. Biochemical fractionation reveals association of DNA methyltransferase (Dnmt) 3b with Dnmt1 and that of Dnmt 3a with a histone $\mathrm{H} 3$ methyltransferase and Hdac1. J. Cell Biochem. 88: 855-864.

De Marzo, A.M., Marchi, V.L., Yang, E.S., Veeraswamy, R., Lin, X., and Nelson, W.G. 1999. Abnormal regulation of DNA methyltransferase expression during colorectal carcinogenesis. Cancer Res. 59: 3855-3860.

Deplus, R., Brenner, C., Burgers, W.A., Putmans, P., Kouzarides, T., de Launoit, Y., and Fuks, F. 2002. Dnmt3L is a transcriptional repressor that recruits histone deacetylase. Nucleic Acids Res. 30: 3831-3838.

Eissenberg, J.C. and Elgin, S.C. 2000. The HP1 protein family: Getting a grip on chromatin. Curr. Opin. Genet. Dev. 10: 204-210.

Fahrner, J.A., Eguchi, S., Herman, J.G., and Baylin, S.B. 2002. Dependence of histone modifications and gene expression 
on DNA hypermethylation in cancer. Cancer Res. 62: 72137218.

Fuks, F., Burgers, W.A., Brehm, A., Hughes-Davies, L., and Kouzarides, T. 2000. DNA methyltransferase Dnmt1 associates with histone deacetylase activity. Nat. Genet. 24: 8891

Fuks, F., Hurd, P.J., Deplus, R., and Kouzarides, T. 2003. The DNA methyltransferases associate with HP1 and the SUV39H1 histone methyltransferase. Nucleic Acids Res. 31: 2305-2312.

Ghoshal, K., Datta, J., Majumder, S., Bai, S., Dong, X., Parthun, M., and Jacob, S.T. 2002. Inhibitors of histone deacetylase and DNA methyltransferase synergistically activate the methylated metallothionein I promoter by activating the transcription factor MTF-1 and forming an open chromatin structure. Mol. Cell. Biol. 22: 8302-8319.

Graff, J.R., Gabrielson, E., Fujii, H., Baylin, S.B., and Herman, J.G. 2000. Methylation patterns of the E-cadherin 5' CpG island are unstable and reflect the dynamic, heterogeneous loss of E-cadherin expression during metastatic progression. J. Biol. Chem. 275: 2727-2732.

Grewal, S.I. and Elgin, S.C. 2002. Heterochromatin: New possibilities for the inheritance of structure. Curr. Opin. Genet. Dev. 12: 178-187.

Hall, I.M., Shankaranarayana, G.D., Noma, K., Ayoub, N., Cohen, A., and Grewal, S.I. 2002. Establishment and maintenance of a heterochromatin domain. Science 297: 2232-2237.

Hwang, K.K., Eissenberg, J.C., and Worman, H.J. 2001. Transcriptional repression of euchromatic genes by Drosophila heterochromatin protein 1 and histone modifiers. Proc. Natl. Acad. Sci. 98: 11423-11427.

Issa, J.P., Vertino, P.M., Wu, J., Sazawal, S., Celano, P., Nelkin, B.D., Hamilton, S.R., and Baylin, S.B. 1993. Increased cytosine DNA-methyltransferase activity during colon cancer progression. J. Nat1. Cancer Inst. 85: 1235-1240.

Jackson, J.P., Lindroth, A.M., Cao, X., and Jacobsen, S.E. 2002. Control of CpNpG DNA methylation by the KRYPTONITE histone H3 methyltransferase. Nature 416: 556-560.

Jacobs, S.A., Taverna, S.D., Zhang, Y., Briggs, S.D., Li, J., Eissenberg, J.C., Allis, C.D., and Khorasanizadeh, S. 2001. Specificity of the HP1 chromo domain for the methylated N-terminus of histone H3. EMBO I. 20: 5232-5241.

Jenuwein, T. 2001. Re-SET-ting heterochromatin by histone methyltransferases. Trends Cell Biol. 11: 266-273.

Jenuwein, T. and Allis, C.D. 2001. Translating the histone code. Science 293: 1074-1080.

Johnson, L., Cao, X., and Jacobsen, S. 2002. Interplay between two epigenetic marks. DNA methylation and histone H3 lysine 9 methylation. Curr. Biol. 12: 1360-1367.

Jones, P.A. and Baylin, S.B. 2002. The fundamental role of epigenetic events in cancer. Nat. Rev. Genet. 3: 415-428.

Kimura, A., Umehara, T., and Horikoshi, M. 2002. Chromosomal gradient of histone acetylation established by Sas $2 p$ and Sir2p functions as a shield against gene silencing. Nat. Genet. 32: 370-377.

Kondo, Y., Shen, L., and Issa, J.P. 2003. Critical role of histone methylation in tumor suppressor gene silencing in colorectal cancer. Mol. Cell. Biol. 23: 206-215.

Kouzarides, T. 2002. Histone methylation in transcriptional control. Curr. Opin. Genet. Dev. 12: 198-209.

Lachner, M. and Jenuwein, T. 2002. The many faces of histone lysine methylation. Curr. Opin. Cell Biol. 14: 286-298.

Lachner, M., O'Carroll, D., Rea, S., Mechtler, K., and Jenuwein, T. 2001. Methylation of histone H3 lysine 9 creates a binding site for HP1 proteins. Nature 410: 116-120.
Li, Y., Kirschmann, D.A., and Wallrath, L.L. 2002. Does heterochromatin protein 1 always follow code? Proc. Natl. Acad. Sci. 99: (Suppl. 4) 16462-16469.

Litt, M.D., Simpson, M., Gaszner, M., Allis, C.D., and Felsenfeld, G. 2001. Correlation between histone lysine methylation and developmental changes at the chicken $\beta$-globin locus. Science 293: 2453-2455.

Lunyak, V.V., Burgess, R., Prefontaine, G.G., Nelson, C., Sze, S.H., Chenoweth, J., Schwartz, P., Pevzner, P.A., Glass, C., Mandel, G., et al. 2002. Corepressor-dependent silencing of chromosomal regions encoding neuronal genes. Science 298: $1747-1752$.

Maison, C., Bailly, D., Peters, A.H., Quivy, J.P., Roche, D., Taddei, A., Lachner, M., Jenuwein, T., and Almouzni, G. 2002. Higher-order structure in pericentric heterochromatin involves a distinct pattern of histone modification and an RNA component. Nat. Genet. 30: 329-334.

Nakayama, J., Rice, J.C., Strahl, B.D., Allis, C.D., and Grewal, S.I. 2001. Role of histone H3 lysine 9 methylation in epigenetic control of heterochromatin assembly. Science 292: $110-113$.

Nguyen, C.T., Weisenberger, D.J., Velicescu, M., Gonzales, F.A., Lin, J.C., Liang, G., and Jones, P.A. 2002. Histone H3lysine 9 methylation is associated with aberrant gene silencing in cancer cells and is rapidly reversed by 5 -aza- 2 '-deoxycytidine. Cancer Res. 62: 6456-6461.

Nielsen, S.J., Schneider, R., Bauer, U.M., Bannister, A.J., Morrison, A., O'Carroll, D., Firestein, R., Cleary, M., Jenuwein, T., Herrera, R.E., et al. 2001. Rb targets histone H3 methylation and HP1 to promoters. Nature 412: 561-565.

Noma, K., Allis, C.D., and Grewal, S.I. 2001. Transitions in distinct histone $\mathrm{H} 3$ methylation patterns at the heterochromatin domain boundaries. Science 293: 1150-1155.

Peters, A.H., O'Carroll, D., Scherthan, H., Mechtler, K., Sauer, S., Schofer, C., Weipoltshammer, K., Pagani, M., Lachner, M., Kohlmaier, A., et al. 2001. Loss of the Suv39h histone methyltransferases impairs mammalian heterochromatin and genome stability. Cell 107: 323-337.

Plath, K., Fang, J., Mlynarczyk-Evans, S.K., Cao, R., Worringer, K.A., Wang, H., de la Cruz, C.C., Otte, A.P., Panning, B., and Zhang, Y. 2003. Role of histone H3 lysine 27 methylation in $\mathrm{X}$ inactivation. Science 300: 131-135.

Rhee, I., Bachman, K.E., Park, B.H., Jair, K.W., Yen, R.W., Schuebel, K.E., Cui, H., Feinberg, A.P., Lengauer, C., Kinzler, K.W., et al. 2002. DNMT1 and DNMT3b cooperate to silence genes in human cancer cells. Nature 416: 552-556.

Richards, E.J. and Elgin, S.C. 2002. Epigenetic codes for heterochromatin formation and silencing: Rounding up the usual suspects. Cell 108: 489-500.

Robertson, K.D., Uzvolgyi, E., Liang, G., Talmadge, C., Sumegi, J., Gonzales, F.A., and Jones, P.A. 1999. The human DNA methyltransferases (DNMTs) 1, 3a and 3b: Coordinate mRNA expression in normal tissues and overexpression in tumors. Nucleic Acids Res. 27: 2291-2298.

Robertson, K.D., Ait-Si-Ali, S., Yokochi, T., Wade, P.A., Jones, P.L., and Wolffe, A.P. 2000. DNMT1 forms a complex with $\mathrm{Rb}, \mathrm{E} 2 \mathrm{~F} 1$ and HDAC1 and represses transcription from E2Fresponsive promoters. Nat. Genet. 25: 338-342.

Rountree, M.R., Bachman, K.E., and Baylin, S.B. 2000. DNMT1 binds HDAC2 and a new co-repressor, DMAP1, to form a complex at replication foci. Nat. Genet. 25: 269-277.

Schultz, D.C., Friedman, J.R., and Rauscher III, F.J. 2001. Targeting histone deacetylase complexes via KRAB-zinc finger proteins: The PHD and bromodomains of KAP-1 form a cooperative unit that recruits a novel isoform of the Mi- $2 \alpha$ subunit of NuRD. Genes \& Dev. 15: 428-443. 
Schultz, D.C., Ayyanathan, K., Negorev, D., Maul, G.G., and Rauscher III, F.J. 2002. SETDB1: A novel KAP-1-associated histone $\mathrm{H} 3$, lysine 9-specific methyltransferase that contributes to HP1-mediated silencing of euchromatic genes by KRAB zinc-finger proteins. Genes \& Dev. 16: 919-932.

Sherr, C.J. 1996. Cancer cell cycles. Science 274: 1672-1677.

Strahl, B.D. and Allis, C.D. 2000. The language of covalent histone modifications. Nature 403: 41-45.

Suka, N., Luo, K., and Grunstein, M. 2002. Sir2p and Sas2p opposingly regulate acetylation of yeast histone $\mathrm{H} 4$ lysine 16 and spreading of heterochromatin. Nat. Genet. 32: 378-383.

Sun, F.L. and Elgin, S.C. 1999. Putting boundaries on silence. Cell 99: 459-462.

Suzuki, H., Gabrielson, E., Chen, W., Anbazhagan, R., van Engeland, M., Weijenberg, M.P., Herman, J.G., and Baylin, S.B. 2002. A genomic screen for genes upregulated by demethylation and histone deacetylase inhibition in human colorectal cancer. Nat. Genet. 31: 141-149.

Tamaru, H. and Selker, E.U. 2001. A histone H3 methyltransferase controls DNA methylation in Neurospora crassa. $\mathrm{Na}$ ture 414: 277-283.

Tilghman, S.M. 1999. The sins of the fathers and mothers: Genomic imprinting in mammalian development. Cell 96: $185-193$.

Tufarelli, C., Stanley, J.A., Garrick, D., Sharpe, J.A., Ayyub, H., Wood, W.G., and Higgs, D.R. 2003. Transcription of antisense RNA leading to gene silencing and methylation as a novel cause of human genetic disease. Nat. Genet. 34: 157165.

Varambally, S., Dhanasekaran, S.M., Zhou, M., Barrette, T.R., Kumar-Sinha, C., Sanda, M.G., Ghosh, D., Pienta, K.J., Sewalt, R.G., Otte, A.P., et al. 2002. The polycomb group protein EZH2 is involved in progression of prostate cancer. $\mathrm{Na}$ ture 419: 624-629.

Volpe, T.A., Kidner, C., Hall, I.M., Teng, G., Grewal, S.I., and Martienssen, R.A. 2002. Regulation of heterochromatic silencing and histone H3 lysine-9 methylation by RNAi. Science 297: 1833-1837.

Wakimoto, B.T. 1998. Beyond the nucleosome: Epigenetic aspects of position-effect variegation in Drosophila. Cell 93: 321-324.

Wallrath, L.L. and Elgin, S.C. 1995. Position effect variegation in Drosophila is associated with an altered chromatin structure. Genes \& Dev. 9: 1263-1277.

Willard, H.F. and Carrel, L. 2001. Making sense (and antisense) of the $\mathrm{X}$ inactivation center. Proc. Natl. Acad. Sci. 98: 10025-10027.

Xin, Z., Tachibana, M., Guggiari, M., Heard, E., Shinkai, Y., and Wagstaff, J. 2003. Role of histone methyltransferase G9a in CpG methylation of the Prader-Willi syndrome imprinting center. J. Biol. Chem. 278: 14996-15000. 


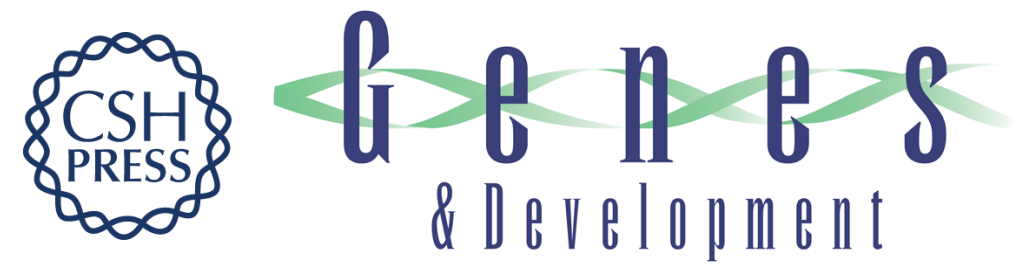

\section{Heterochromatin: stable and unstable invasions at home and abroad}

Jill A. Fahrner and Stephen B. Baylin

Genes Dev. 2003, 17:

Access the most recent version at doi:10.1101/gad.1123303

References This article cites 65 articles, 26 of which can be accessed free at: http://genesdev.cshlp.org/content/17/15/1805.full.html\#ref-list-1

License

Email Alerting Receive free email alerts when new articles cite this article - sign up in the box at the top Service right corner of the article or click here.

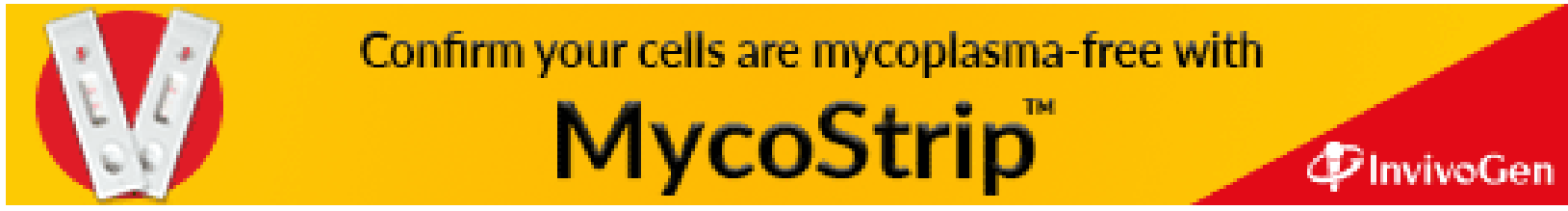

